\title{
QUANTIFICATION OF TRYPTOPHAN IN PLASMA BY HIGH PERFORMANCE LIQUID CHROMATOGRAPHY
}

\author{
Renata Romanholi Pinhati, Hudson Caetano Polonini, Marcos Antônio Fernandes Brandão e Nádia Rezende Barbosa \\ Raposo* \\ Faculdade de Farmácia, Universidade Federal de Juiz de Fora, Rua José Lourenço Kelmer, s/n, 36036-330 Juiz de Fora - MG, Brasil \\ Felipe Corchs e Wagner Farid Gattaz \\ Departamento e Instituto de Psiquiatria, Faculdade de Medicina, Universidade de São Paulo, 01246-903 São Paulo - SP, Brasil
}

Recebido em 15/6/11; aceito em 16/9/11; publicado na web em 3/11/11

\begin{abstract}
A simple, rapid and selective method using high-performance liquid chromatography with ultraviolet detection ( $267 \mathrm{~nm})$ was applied for the determination of tryptophan in plasma. Separation was carried out on a C18 column (150 x $4.6 \mathrm{~mm}$ internal diameter) in 6 $\mathrm{min}$. The mobile phase consisted of $5 \mathrm{mM}$ the sodium acetate and acetonitrile $(92: 8, \mathrm{v} / \mathrm{v})$. The method was shown to be precise and accurate, and good recovery of analyte was achieved, characterizing the method as efficient and reliable for use in laboratory analysis.
\end{abstract}

Keywords: tryptophan; serotonin; HPLC.

\section{INTRODUCTION}

Tryptophan (Figure 1) is an essential human amino acid that acts predominantly as the precursor of serotonin (5-HT), an important neurotransmitter with physiological activity. ${ }^{1}$ It has a role in physiological (nerve transmission, immune response) and pathological processes (depression, stress, and sleep and appetite disorders) ${ }^{2}$ and therefore its plasma levels are linked to changes in mood, behavior, anxiety, sleep, fatigue and appetite suppression. ${ }^{3}$ These characteristics have led research centers to focus their studies on the creation of methods allowing the determination and quantification of this amino acid, as well as the identification of possible relationships between plasma levels of tryptophan with diseases and metabolic disorders.<smiles>N[C@@H](Cc1c[nH]c2ccccc12)C(=O)O</smiles>

Figure 1. Chemical structure of tryptophan $\left(\mathrm{C}_{11} \mathrm{H}_{12} \mathrm{~N}_{2} \mathrm{O}_{2}\right)$

Various methods and techniques for quantifying these tryptophan plasma levels have been developed over the years, such as direct spectrophotometric analysis, colorimetric methods, ${ }^{4}$ electrospray ionization tandem mass spectrometry ${ }^{5}$ and high performance liquid chromatography (HPLC). This latter approach become the technique of choice for analysis, because of its speed, efficiency and excellent separation for both the amino acid and its metabolites. ${ }^{6}$ In methods using this technique, different detectors have been described, namely: mass spectrometry, ${ }^{5,7}$ fluorescence,,${ }^{1,8,9}$ fluorimetric ${ }^{10}$ and ultraviolet. ${ }^{11,12}$

Given the importance of tryptophan in various human physiological functions and the methods available in the literature, we sought through this work to develop a simple and rapid method for quantification of tryptophan in human plasma using HPLC technique with photodiode array (PDA) detection. Quantification in humans can aid the understanding of the pathophysiology of depression and other psychiatric disorders, and serves to assess the nutritional content of the diet of patients who have a predisposition to low 5-HT plasma levels. In addition, the reduced use of organic solvents of the proposed

*e-mail: nadiafox@gmail.com technique provides economy for laboratories and generates residues less harmful to the environment.

\section{EXPERIMENTAL}

\section{Reagents and materials}

All reagents were of analytical grade and solvents were of chromatography purity. The sodium acetate and perchloric acid were from Merck (Darmstadt, Germany), the acetonitrile from Tedia (Fairfield, USA) and L-tryptophan (98\% purity), used as standard substance was kindly donated as a gift by Ajinomoto (São Paulo, Brazil). Freshly prepared ultrapure water was obtained in-house using a Master System purification device from Gehaka (São Paulo, Brazil).

\section{Standard preparation}

A tryptophan stock solution was prepared at a concentration of $0.04 \mathrm{mg} \mathrm{mL}^{-1}$ in mobile phase. Throughout the assay, working solutions were prepared from the stock solution, diluted in human plasma to concentrations of $0.5,2.5,5.0,7.5,15.0,25.0$ and $30.0 \mu \mathrm{g} \mathrm{mL}^{-1}$, according to the necessity of each validation test, and used fresh for each analysis.

\section{Sample treatment}

Eight patients were selected from a psychiatric clinic and basic health units and underwent two tests. The difference between the tests was the presence or absence of tryptophan in the mixture of amino acids to be ingested by the patients (namely tryptophan depletion, TD). Samples were collected at 8:30 am for determination of tryptophan baseline parameters. At 9:00 am, a mixture of amino acids (with or without tryptophan, according to the phase of the study) was administered to the patients. At 3:30 pm, a further collection was performed to determine the occurrence of depletion of tryptophan basal levels in relation to the baseline measurements obtained at 8:30 am. ${ }^{13}$

The collection was carried out by venipuncture in vacutainer tubes containing ethylenediamine tetraacetic acid (EDTA) solution as the anticoagulant. After centrifugation of the blood, the plasma was transferred to glass tubes and stored at $-80^{\circ} \mathrm{C}$ until analysis. Prior to analysis, the plasma $(500 \mu \mathrm{L})$ was subjected to deproteinization with 
$8 \%$ perchloric acid $(50 \mu \mathrm{L})$ solution, ${ }^{14}$ vortexed for $1 \mathrm{~min}$ and finally centrifuged for $15 \mathrm{~min}$ at $1200 \mathrm{x} \mathrm{g}$, thermostatted at $4{ }^{\circ} \mathrm{C}$. A volume of $25 \mu \mathrm{L}$ of the supernatant was injected into the HPLC system.

This experimental protocol was established in accordance with the Declaration of Helsinki and was approved by the Research Ethics Committee of the University of São Paulo (Approval no. 538/05).

\section{Chromatographic conditions}

Liquid chromatography was carried out on a Shimadzu (Tokyo, Japan) high performance liquid chromatography system equipped with a diode array SPD-10A vp detector set at $267 \mathrm{~nm}$. Separation was carried out in a $C_{18}(150 \times 4.6 \mathrm{~mm}, 5 \mu \mathrm{m}$ particle size $)$ column from Nova Analítica (São Paulo, Brazil), maintained at room temperature. For the robustness study, a CLC-CN Shimadzu column $(150 \times 4.6 \mathrm{~mm}$, $5 \mu \mathrm{m}$ particle size) was again used. The mobile phase consisted of an aqueous solution of sodium acetate $(\mathrm{AcNa})(5 \mathrm{mM})$ and acetonitrile $(\mathrm{ACN})(92: 8, \mathrm{v} / \mathrm{v}), \mathrm{pH}=7.15$. The flow rate was adjusted to $1 \mathrm{~mL}$ $\mathrm{min}^{-1}$ in an isocratic elution. Data acquisition and interpretation were performed using CLASS-Vp version 5.42 software.

\section{Method validation}

The method was fully validated for the parameters: linearity, limit of detection (LOD), limit of quantification (LOQ), specificity, precision, accuracy, stability, recovery and robustness. ${ }^{15}$

The linearity of the method was evaluated through the preparation of standard solutions of tryptophan in blank human plasma at concentrations of $0.5,7.5,15.0,25.0$ and $30.0 \mu \mathrm{g} \mathrm{mL} \mathrm{m}^{-1}$. Within this aim, values of each concentration level were statistically evaluated using analysis of variance (ANOVA) ${ }^{16}$ and the value of the correlation coefficient of the analytical curve.

The limit of detection (LOD) was estimated mathematically as three times the standard deviation of the y-intercept, the result being divided by the slope of the calibration curve. The limit of quantification (LOQ) was calculated as ten times the standard deviation of the y-intercept, the result being divided by the slope of the calibration curve. ${ }^{15}$

The specificity was evaluated comparing the retention time of the tryptophan standard substance spiked in lipemic, hemolysate and natural plasma samples, to prove that the method provides selective and specific determination of tryptophan.

The precision study comprised repeatability (intra-day precision) and intermediate precision (inter-day precision) studies. The intra-day precision was estimated on three concentrations of tryptophan (2.5, 5.0 and $15.0 \mu \mathrm{g} \mathrm{mL}^{-1}$ ) and determined in five samples in a day, while inter-day precision was determined by measuring the same sample on three consecutive days.

The accuracy of the method was determined through the analysis of the plasma samples spiked with the tryptophan standard substance, at three different concentrations: $2.5,5.0,15.0 \mu \mathrm{g} \mathrm{mL}-1(\mathrm{n}=5$, for each concentration).

Stability of the working solutions (biological matrix and standard solution) was evaluated under the following storage conditions: room temperature $\left(18^{\circ} \mathrm{C}\right)$ for $24 \mathrm{~h} ; 4^{\circ} \mathrm{C}$ for 7,15 and 30 days, $-20^{\circ} \mathrm{C}$ for 7, 15 and 30 days, and $-80^{\circ} \mathrm{C}$ for 30 days.

Recovery was estimated by the chromatographic analyses of pool plasma before and after the spiking of standard solutions of tryptophan, in the concentrations of 5.0, 10.0 and $25.0 \mu \mathrm{g} \mathrm{mL}^{-1}$. Sample recovery was expressed as: $\{[$ (experimental concentration - pool plasma concentration) /spiked amount] x 100\}.

The robustness of the method was evaluated by varying method parameters such as mobile phase and its flow rate as well as the packing of the chromatographic columns.

\section{RESULTS AND DISCUSSION}

Several methods have been reported for the determination of tryptophan in human plasma by HPLC, which has become the technique of choice for this amino acid. ${ }^{1,4,8,11,14,17}$ However, the chromatographic techniques are well-known for their use (sometimes in large quantities) of environmentally hazardous organic solvents and can affect human health. ${ }^{18}$ Current recommendations encouraged the use of smaller amounts of these solvents (or none), aiming to achieve safer methods of analysis, without compromising their performance: this can be considered the pillar of the so-called "green chemistry". ${ }^{19}$

A typical chromatogram obtained with extracted plasma sample spiked with the tryptophan standard substance is shown in Figure 2, where the good retention time $\left(t_{R}\right)$ of 5.1 min can be observed. As the patients were subjected to other treatments (concurrent administration of fluoxetine, sertraline, paroxetine or citalopram) during the experiment, a pool of their plasma before tryptophan administration was obtained and injected into the chromatograph. The blank human sample chromatogram can be observed in Figure 2, and confirms no interference in tryptophan retention time.

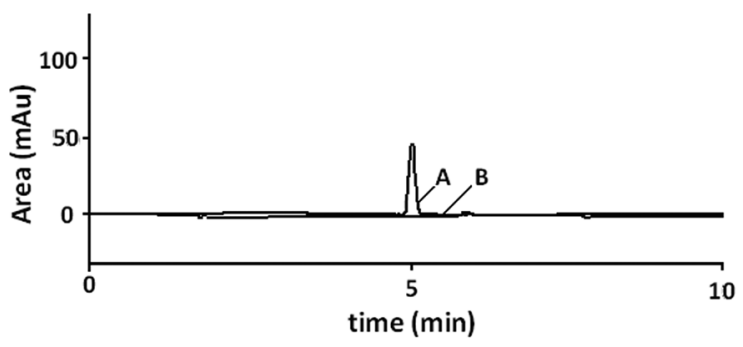

Figure 2. Chromatogram of: (A) tryptophan standard solution, at a concentration of $2.5 \mu \mathrm{g} \mathrm{mL}^{-1}$; and (B) blank human plasma

In the present work, the chromatographic runs were completed in $10 \mathrm{~min}$, despite the 5-min tryptophan retention time. This was done for academic purposes, to verify whether other compounds would be detectable by the method, which proved not the case. However, in the laboratory routine the runs can be completed in $6 \mathrm{~min}$, a plausible and short time for an HPLC method for a biological matrix.

The calibration curve was obtained through experiments performed in duplicate, and yielded the statistical model: y $( \pm 3591.22)$ $=29976.76( \pm 86.79) \mathrm{x}-1026.19( \pm 1649.75)$, with $\mathrm{R}^{2}=0.99993$. The linearity of the method was also evaluated through analysis of variance, as shown in Table 1.

Table 1. Analysis of variance for fitting the model of prediction for the validation study

\begin{tabular}{lccc}
\hline Source & $\begin{array}{c}\text { Sum of Square } \\
(\mathrm{SS})\end{array}$ & $\begin{array}{c}\text { Number of degrees } \\
\text { of freedom }\end{array}$ & $\begin{array}{c}\text { Mean of Square } \\
(\mathrm{MS})\end{array}$ \\
\hline Model & $1.06 \times 10^{12}$ & 1 & $1.06 \times 10^{12}$ \\
Residual & $7.10 \times 10^{7}$ & 8 & $8.88 \times 10^{6}$ \\
Lack of fit & $5.46 \times 10^{7}$ & 3 & $1.82 \times 10^{7}$ \\
Pure error & $1.64 \times 10^{7}$ & 5 & $3.28 \times 10^{6}$ \\
Total & $1.06 \times 10^{12}$ & 9 & $1.06 \times 10^{12}$ \\
\hline
\end{tabular}

$\%$ variation explained by regression $=99.99 ; \%$ maximum of variation explained $=99.99$

The test of significance of regression gave the value of $\mathrm{F}_{\text {calculated (MS model } / \mathrm{MS} \text { residual) }}=119289.08$, larger than $\mathrm{F}_{\text {critical } 0.05, v 1=1, v 2=8}=$ 5.32 , which confirms the existence of a significant linear relationship between the two variables, with $95 \%$ confidence. The test of lack of fit returned the value of $\mathrm{F}_{\text {calculated (MSl ack of fit/MS pure error) }}=5.55$, larger than 
$\mathrm{F}_{\text {critical } 0.05, v 1=3, v 2=5}=5.41$, with $95 \%$ confidence. Through these results, one can observe that there is lack of fit in the method, however the percentage of explained variation is very close (mathematically equal) to the maximum that can be applied by the model. Thus, the results upon using the equation of the model to predict tryptophan concentrations will be very close to the real values in the samples.

The LOD was $0.27 \mu \mathrm{g} \mathrm{mL} \mathrm{m}^{-1}$ of tryptophan and the LOQ was $0.50 \mu \mathrm{g} \mathrm{mL} \mathrm{m}^{-1}$ (coefficient of variation, $\mathrm{CV},=1.98 \%$ and standard deviation, $\mathrm{SD},=0.01$, for five replicates).

The specificity of the method was obtained through the comparison among the sample chromatograms of natural, lipemic and hemolysate plasmas spiked with tryptophan, and no other peak was observed near its retention time, as shown in Figure 3. The plasma samples, spiked with tryptophan at the following concentrations: natu$\operatorname{ral}\left(2.5 \mathrm{~g} \mathrm{~mL}^{-1}\right)$, lipemic $\left(7.5 \mu \mathrm{g} \mathrm{mL}^{-1}\right)$, and hemolysate $\left(7.5 \mathrm{mg} \mathrm{mL}^{-1}\right)$, were individually injected into the chromatograph. Through this test and the blank human plasma chromatogram (Figure 2), it was observed that there is no endogenous component of the biological matrix that prevents the detection/ quantification of tryptophan.

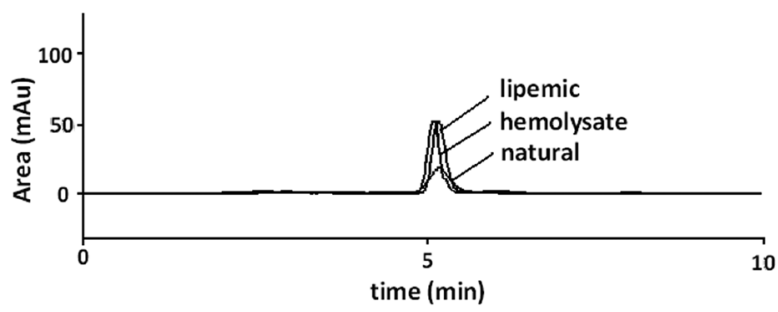

Figure 3. Chromatographic profile of plasma samples spiked with tryptophan at the following concentrations: natural $\left(2.5 \mathrm{~g} \mathrm{~mL}^{-1}\right)$, lipemic $\left(7.5 \mu \mathrm{g} \mathrm{mL}^{-1}\right)$, and hemolysate (7.5 $\mathrm{mg} \mathrm{mL}^{-1}$ )

The precision of the method was calculated from intra- and inter-day measurements for three concentrations $(2.5,5.0$ and 15.0 $\mu \mathrm{g} \mathrm{mL} \mathrm{L}^{-1}$ ), as shown in the Table 2 .

The accuracy of the method was found to be $104.13 \%$ at the level of $2.5 \mu \mathrm{g} \mathrm{mL} \mathrm{g}^{-1}, 99.54 \%$ at the level of $5.0 \mu \mathrm{g} \mathrm{mL}^{-1}$ and $100.78 \%$ at the level of $15.0 \mu \mathrm{g} \mathrm{mL}^{-1}$, in relation to the spiked amount of tryptophan in the samples.

With regard to stability, tryptophan standard solutions in mobile phase remained stable for $6 \mathrm{~h}$ at room temperature, and for 7 days at $-20^{\circ} \mathrm{C}$. In plasma, stability was verified as only $2 \mathrm{~h}$ at room temperature. Between -20 and $-80^{\circ} \mathrm{C}$ the tryptophan did not present stability, because there was loss $\geq 10 \%$ in the value of the concentration of the sample compared with the measured value before storage.

The recovery of the method was estimated by spiking the tryptophan standard in plasma at concentrations of 5.0, 10.0 and
Table 2. Precisions of intra-day and inter-day determination of plasma tryptophan

\begin{tabular}{lccc}
\hline $\begin{array}{l}\text { Concentration } \\
\left.(\mu \mathrm{g} \mathrm{mL})^{-1}\right)\end{array}$ & $\begin{array}{c}\text { Meann } \\
\left(\mu \mathrm{g} \mathrm{m}^{-1}\right)\end{array}$ & $\begin{array}{c}\mathrm{SD} \\
\left(\mu \mathrm{gL} \mathrm{mL}^{-1}\right)\end{array}$ & $\begin{array}{c}\mathrm{CV} \\
(\%)\end{array}$ \\
\hline Intra-day $(\mathrm{n}=5)$ & & & \\
2.5 & 2.60 & 0.01 & 0.26 \\
5.0 & 4.97 & 0.03 & 0.72 \\
15.0 & 15.11 & 0.20 & 1.30 \\
Inter-day (n=15) & & & \\
2.5 & 2.54 & 0.10 & 3.97 \\
5.0 & 4.88 & 0.16 & 3.29 \\
15.0 & 14.80 & 0.45 & 3.07 \\
\hline
\end{tabular}

$\overline{\mathrm{n}}=$ number of analyzed samples; $\mathrm{SD}$, standard deviation; $\mathrm{CV}$, coefficient of variation.

$25.0 \mu \mathrm{g} \mathrm{mL} \mathrm{m}^{-1}$. The recovery results found for the samples were within the range of $94.32-99.80 \%(\mathrm{CV}<2.00 \%)$.

To evaluate robustness, the following parameters were tested: effect of the content of organic solvent in the mobile phase, effect of flow rate of the mobile phase and packing of the chromatographic column (porous silica particles bonded to octadecyl silane $-\mathrm{C}_{18}$ - or to nitrile groups $-\mathrm{CN}$ ). The standard solutions of tryptophan were analyzed and tested using the mobile phase containing different amounts of $\operatorname{ACN}(1,2$ and $8 \%)$. With increasing amounts of ACN retention time decreased. Using the mobile phase containing $8 \% \mathrm{ACN}$, the peak area was increased, but the mobile phase containing only acetate buffer or $1 \% \mathrm{ACN}$ did not elute the tryptophan. Retention time was decreased by increasing the flow rate to $1.5 \mathrm{~mL} \mathrm{~min}^{-1}$. In addition, no chromatographic peak was observed when using the $\mathrm{CN}$ column.

Thus, mobile phase consisted of a $5 \mathrm{mM}$ sodium acetate - acetonitrile $(92: 8, \mathrm{v} / \mathrm{v})$ solution, flow-rate of $1 \mathrm{~mL} \mathrm{~min}^{-1}$ and the analytical column $\mathrm{C}_{18}$ were characterized as optimal conditions for the implementation of the analytical method in terms of selectivity, acceptable precision and accuracy. In addition, it is worth emphasizing the small percentage of acetonitrile used by the method compared with other robust methods that use large amounts of organic solvent.

After the validation process, plasma samples from the patients were submitted to quantification of tryptophan. Patients submitted to ingestion of the mixture not containing tryptophan (TD) had plasma concentrations ranging from 3.08 to $7.81 \mu \mathrm{g} \mathrm{mL}^{-1}(8: 30 \mathrm{am})$ and between 0 and $4.79 \mu \mathrm{g} \mathrm{mL}^{-1}(3: 30 \mathrm{pm})$. Patients who drank the mixture containing tryptophan had plasma concentrations ranging from 3.02 to $8.90 \mu \mathrm{g} \mathrm{mL}^{-1}(8: 30 \mathrm{am})$ and from 5.69 to $18.70 \mu \mathrm{g} \mathrm{mL}^{-1}(3: 30 \mathrm{pm})$. The individual results are shown in Table 3.

In this study, the results of tryptophan plasma levels in patients undergoing TD showed significant differences in relation to the two

Table 3. Tryptophan plasma level determined from patients samples

\begin{tabular}{|c|c|c|c|c|}
\hline \multirow[b]{2}{*}{ Patients } & \multicolumn{2}{|c|}{ Mixture of amino acid without tryptophan } & \multicolumn{2}{|c|}{ Mixture of amino acid with tryptophan } \\
\hline & $\begin{array}{c}\text { Plasma level } \\
\left(\mu \mathrm{g} \mathrm{mL} L^{-1}\right) \\
8: 30 \mathrm{am} \\
\end{array}$ & $\begin{array}{c}\text { Plasma level } \\
\left(\mu \mathrm{g} \mathrm{mL} \mathrm{m}^{-1}\right) \\
3: 30 \mathrm{pm} \\
\end{array}$ & $\begin{array}{c}\text { Plasma level } \\
\left(\mu \mathrm{g} \mathrm{mL} \mathrm{m}^{-1}\right) \\
8: 30 \mathrm{am} \\
\end{array}$ & $\begin{array}{c}\text { Plasma level } \\
\left(\mu \mathrm{g} \mathrm{mL} L^{-1}\right) \\
3: 30 \mathrm{pm} \\
\end{array}$ \\
\hline 1 & 5.66 & 2.97 & 8.90 & 18.70 \\
\hline 2 & 3.08 & 1.13 & 4.39 & 9.29 \\
\hline 3 & 6.83 & 4.79 & 3.98 & 5.69 \\
\hline 4 & 6.30 & not detectable & 5.93 & 8.22 \\
\hline 5 & 2.25 & not detectable & 8.87 & 14.98 \\
\hline 6 & 7.81 & not detectable & 6.83 & 10.12 \\
\hline 7 & 4.42 & not detectable & 3.02 & 7.28 \\
\hline 8 & 5.05 & not detectable & 6.25 & 9.07 \\
\hline
\end{tabular}

samples analyzed in duplicate. 
scheduled times in the test. The patients who ingested a mixture of amino acids that did not contain tryptophan had reduced or undetectable plasma levels - compared to patients who ingested a mixture containing tryptophan.

It was observed therefore that the determination of plasma levels of tryptophan can be used successfully to further understanding of the pathophysiology of depression and to investigate psychiatric disorders. The method also allows assessments to be made regarding the nutritional content of the diet of patients who have a predisposition to low 5-HT plasma levels. The method proposed in this work is applicable for the determination of tryptophan in human plasma, since it proved able to quantify the amino acid in the biological matrix.

\section{CONCLUSIONS}

The method proposed in this work is applicable for the determination of tryptophan in human plasma, since it proved able to quantify the amino acid in the biological matrix. The presented method is simple, rapid and accurate, and is not subject to interference of other molecules that absorb in the ultraviolet region. In addition, the method is environmentally-friendly due to the small amount of organic solvent needed in the mobile phase. The lower use of organic solvents also provides greater economy.

\section{ACKNOWLEDGMENTS}

The authors are grateful to FAPEMIG and FAPESP.

\section{REFERENCES}

1. Zhang, J. Z.; Xue, X. F.; Zhou, J. H.; Chen, F.; Wu, L.; Li, Y.; Zhao, J.; Biomed. Chrom. 2009, 23, 994.

2. Molnár-perl, I.; Int. Congr. Ser. 2007, 1304, 389.

3. Del bem, C. M.; Rev. Psiquiatr. Clin. 2005, 32, 27.

4. Yust, M. M.; Pedroche, J.; Giron-calle, J.; Vioque, J.; Millan, F.; Alaiz, M.; Food Chem. 2004, 85, 317.
5. Yamada, K.; Miyazaki, T.; Shibata, T.; Hara, N.; Tsuchiya M.; J. Chromatogr., B: Anal. Technol. Biomed. Life Sci. 2008, 867, 57.

6. Marklová, E.; Makovicková, H.; Krákorová, I.; J. Chromatogr., A 2000, $870,289$.

7. Arvidsson, B.; Johannesson, N.; Citterio, A.; Righetti, P. G.; Bergquist. J.; J. Chromatogr., A 2007, 1159, 154; Schefold, J.; Zeden, J. P.; Fotopoulou, C. V. H. S.; Pschowski, R.; Hasper, D.; Nephrol. Dial. Transpl. 2009, 24, 1901 .

8. Andrade, C. D.; Henares, J. A. R.; Pérez, S. J.; Morales, F. J.; Food Chem. 2006, 98, 580 .

9. Luo, X. B.; Tang, A. G.; Pi, L. G.; Xiao, L. D.; Pu, Y. H.; Clin. Chim. Acta. 2008, 389, 186.

10. Martins, A. C. C. L.; Silva, T. M.; Gloria, M. B. A.; Quim. Nova. 2010 , $33,316$.

11. Wang. R.; Aiguo, T.; Chin. J. Chromatogr. 2006, 24, 140.

12. Ma, L.; Xu, B.; Wang, W.; Deng, W.; Ding, M.; Clin. Chim. Acta. 2009, $405,94$.

13. Corchs, F.; Nuttb, D. J.; Hoodbc, S.; Bernika, M.; Biol. Psychiatry 2009, $66,17$.

14. Vignau, J.; Jacquemont, M. C.; Lefort, A.; Imbenotte, M.; Lhermitte, M.; Biomed. Chromatogr. 2004, 18, 872.

15. Brasil, Agência Nacional de Vigilância Sanitária; Resolução RE n. 899, 2003, disponível em ??? ou publicada em ???

16. Montgomery, D. C.; Design and Analysis of Experiments, $6^{\text {th }} \mathrm{ed}$, Wiley: New York, 2004; Barros Neto, B.; Scarminio, I. S.; Bruns, R. E.; Como fazer experimentos: pesquisa e desenvolvimento na ciência e na indústria, $4^{\mathrm{a}}$ ed.; Bookman: Porto Alegre, 2010.

17. Lan-Gan, P.; Ai-Guo, T.; Xi-Ming, M.; Xi-Bo, L.; Xiang, ??; Clin. Biochem. 2009, 42, 420; Zhang, X.; He, Y.; Ding, ??; J. Chromatogr., B: Anal. Technol. Biomed. Life Sci. 2009, 877, 1678; Li, Y.; Tang, A. G.; Mu, S.; Clin. Chim. Acta 2011, 412, 1032.

18. Sandra, P.; Vanhoenacker, G.; David, F; Sandra, K.; Pereira, A.; LCGC Eur. 2010, 23, falta página.

19. Zhu, L.; Ding, L.; Zhang, Q.; Wang, L.; Tang, F.; Liu, Q.; Yao. S.; Green Chem. 2009, 11, 132. 